Published with Open Access at Journal BiNET

Vol. 02, Issue 02: 125-131

International

Journal BiNET

scientific Publication

Journal of Business, Management and Social Research

Journal Home: www.journalbinet.com/ijbmsr-journal.html

\title{
Diffusion of agricultural innovation through opinion leadership
}

\author{
Islam, K. A. ${ }^{1}$, Bashar, M. A. ${ }^{2}$, Akhter, N. ${ }^{3}$, Mia, M. A. T. ${ }^{4}$, Afroj, M. ${ }^{5}$, Rahman, M. M. ${ }^{6}$ and \\ Baque, M. A. ${ }^{6}$
}

${ }^{1}$ Bangladesh Bank, Khulna

${ }^{2}$ Dept. of Agricultural Extension and Information system, Faculty of Agriculture, Sher-e-Bangla

Agricultural University, Dhaka-1207

${ }^{3}$ Dept. of Agricultural Botany, Faculty of Agriculture, Sher-e-Bangla Agricultural University, Dhaka1207

${ }^{4}$ Dept. of Agricultural Science, Dhaka Residential Model College, Dhaka

${ }^{5}$ Dept. of Agribusiness and Marketing, Faculty of Agribusiness Management, Sher-e-Bangla Agricultural University, Dhaka-1207

${ }^{6}$ Dept. of Agronomy, Faculty of Agriculture, Sher-e-Bangla Agricultural University, Dhaka-1207,

Bangladesh

\begin{abstract}
The aim of the study was to determine the role of opinion leadership in diffusion of agricultural innovation. The study was performed in the Alamdanga Upazila under Chuadanga district. Among the unions of Alamdanga Upazila Kalidaspur union has been selected as the study area. Fifty five farmers were randomly selected to explore the opinion leader. Thus 165 names of opinion leaders were found. After cross checking and deducted the duplicate name a list was prepared with 138 local leaders and communicate with them for interviewing and bring into being available 115. Among the respondents, the highest 54.80 percent respondent opinion leaders belongs to the group of lowest role in diffusion of agricultural innovation followed by 34.80 percent in moderate role group and the lowest percentage 10.40 percent $n$ highest group in diffusion of agricultural innovation. Education level, extent of advice on adoption of agricultural innovation, innovativeness, organization participation, agricultural knowledge, motivational activities and diffusion network had significantly positive relationships with role of opinion leadership in diffusion of agricultural innovation. Annual income had no significant positive relationships with role of opinion leadership in diffusion of agricultural innovation. Besides, age and family size of the respondents had no significant negative relationship with role of opinion leadership in diffusion of agricultural $1^{\text {st }}$ and serve as center of inter personal communication network in positioned $10^{\text {th }}$ as per in case ofrole of opinion leadership in diffusion of agricultural innovation.
\end{abstract}

Key Words: Leadership, Diffusion and Innovation

Cite article: Islam, K. A., Bashar, M. A., Akhter, N., Mia, M. A. T., Afroj, M., Rahman, M. M. \& Baque, M. A. (2016) Diffusion of agricultural innovation through opinion leadership. International Journal of Business, Management and Social Research, 02(02), 125-131.

This article is distributed under terms of a Creative Common Attribution 4.0 International License. 


\section{Introduction}

Bangladesh is an agricultural country with an area of 147,570 square kilometer and has 14.1 million hectares of crop area. Agriculture contributes about 1,770,046 million taka of Gross Domestic Product (GDP) (BBS, 2015) and provides employment for more than two fifth of labor force and contributes large proportion of foreign exchange to the national economy. Agricultural research has developed useful innovations, which are very helpful to increase agricultural production all over the world. However, farmers are mostly illiterate and traditional; they are often unaware about new ideas and practices in agriculture. Therefore, the communication of the benefit is the prerequisite for agricultural development and knows about improved agricultural practices so that they can use them in crop production. Rural development depends on both technology generation and dissemination of technology as per the needs of the target groups (Mettric, 1993). Farmers are the end users of the newly developed technologies. They live in a society and they cannot decide to adopt technology by their own decisions. There is social structure, social norms, opinion leaders, authority and some other powers which influence them in their innovation decision. Some diffusion agencies- government, nongovernment or private involve themselves to spread the technological information among client system. Innovation means newly introduced method or device which has some production potentials and recommended by a recognized authority for a social systems (Bhuiyan, 2012). Newly introduced crop varieties, fertilizers, method of pest control etc. are considered as agricultural innovation. Diffusion is a process of communicating innovation through certain channels over time among the members of a society (Rogers, 1983). Rogers (2003) defined diffusion of an innovation as the "process by which an innovation is communicated through certain channels over time among the members of a social system," whereas an innovation itself is "an idea, practice, or object that is perceived as new by an individual or other unit of adoption". Heemskerk (2005) observed that agricultural innovations are changing to be more demand driven to respond to farmers' needs. Farmers need to be active participants of the development and diffusion of innovations to make adoption happen. Opinion leadership is importantly necessary for diffusion of innovation. Opinion leaders are heterophilous individuals who observe and evaluate innovations proven by innovators. They are considered "early adopters of culturally acceptable innovations and generally are opponents of culturally unacceptable ones" (Monge et al., 2008). Dennis and Andersion (1998) reports regardless of their source and socio economic status, farmers will adopt new technologies and modify their resource use when they believe that a proposed change is relevant to their circumstances and can help them to achieve their objectives. There are some people in the rural areas with leadership qualities. Activities of the farmers are influenced by the opinion leaders from whom they seek information and advice. Generally, opinion leaders of a community are lieutenant of extension agents of that locality. Extension programs can receive greater acceptance and participation of the people by their leader's involvement in programs. Opinion leadership is the way to which an individual is able informally to influence other individual in a desired way with relative frequency (Rogers, 1983). Therefore present study was conducted with the objectives are (1) To determine the role of opinion leadership in diffusion of agricultural innovation, (2) To identify and describe the characteristics of identified opinion leaders. (3) To identify the relationship between selected characteristics of opinion leaders and their role in diffusion of innovation and (4) To prepare a rank order of role of opinion leadership in diffusion of agricultural innovation.

\section{Methodology}

The study was performed in Kalidaspur union of Alamdanga Upazila under Chuadanga District. An update list of 556 farmers of Kalidashpur Union was collected from Upazila Agriculture Office of Alamdanga Upazila. Among them 55 farmers at the rate of $10 \%$ were randomly selected to explore the opinion leaders. The selected 55 farmers were brought together unofficially in a discussion sleeting. Each farmer was asked to mention 3 names from whom they seek advice and suggestions for their family affairs, agricultural matters, marketing and other social matters. Thus 165 names of opinion leaders were found. After cross checking, 27 of duplicate names were found in the list which were discarded and communicated with them for interviewing. Thus, 138 names were found as local leaders. Out of which 115 were available at the time of interview. Thus these 115 local leaders constituted the sample of the study. Data were collected through interview schedule. Role of opinion leadership in diffusion of agricultural innovation was considered as dependent variable. Age, level of 
education, family size, annual income, extent of advice on adoption of agricultural innovation, innovativeness, organizational participation, agricultural knowledge, motivational activities, and diffusion network were considered as independent variables. Age of a opinion leader was calculated by the period of time from his/her birth to interview and it was calculated in terms of complete years on the basis of their response. Level of education was measured in terms of class passed by respondent opinion leader. The family size of a respondent was measured in terms of total number of family members in his family including himself, spouse, children, siblings, parents and other person who jointly live and ate together. The term annual income refers to the annual gross income of a respondent opinion leader himself and the members of his family from different sources. It was expressed in taka. Extent of advice on adoption of agricultural innovation of the respondent opinion leaders was calculated on the basis of the type of activities through which they advice to their fellow farmers. Innovativeness of the opinion leader was measured on the basis of using different technologies as duration after hearing of the technology. Organizational participation of respondent opinion leader was calculated on the basis of the nature of his participation in a selected organization. Agricultural knowledge of an opinion leader was measured by asking thirty questions on different aspect of agriculture to the respondent opinion leaders. Motivational activities of opinion leaders were measured on the basis of 10 different defined activities and the extent of motivation. Diffusion network of an opinion leader was measured by computing a network source score. A total of 14 items of diffusion network source were used for the calculation of diffusion network. For measuring the role of opinion leadership in diffusion of agricultural innovation the roles of opinion leadership in diffusion of agricultural innovation were first identified. In this regard 10 roles of opinion leaders were recorded. Thus total role of opinion leader score was calculated by summing up all the obtaining scores against each role. The score then could range from 030 , where 0 indicated no role performance and 30 indicated high role performance.

Role playing index was constituted with 10 leadership activities using the following formula:

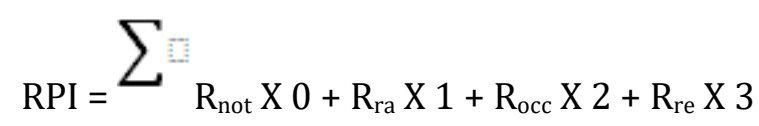

Where,

$\mathrm{R}_{\text {not }}=$ Score of opinion leaders playing not any extent role

$\mathrm{R}_{\mathrm{ra}}=\mathrm{Score}$ of opinion leaders playing rarely extent role

$\mathrm{R}_{\mathrm{occ}}=$ Score of opinion leaders playing occasionally extent role

$\mathrm{R}_{\mathrm{re}}=$ Score of opinion leaders playing regularly extent role

Null hypothesis was formulated as: "There are no relationships between each of 10 selected characteristics of the opinion leaders and their role in diffusion of agricultural innovation". Data collection was started in 07 October, 2014 and completed in 12 November, 2014. After data collection all were compiled, tabulated and analyzed according to the goal of the study. SPSS were used for analyzing the data. Descriptive analysis such as mean, median, mode, standard deviation was used whenever necessary. Pearson's product moment correlation was used in for exploring the relationship between concerned variables.

\section{Results and Discussion}

\section{Role of opinion leadership in diffusion of agricultural innovation}

Role of opinion leadership in diffusion or agricultural innovation is the dependent variable of this study. Role of opinion leadership in diffusion of agricultural innovation was calculated on the basis of 10 specific roles with 4 level of extent of activity. The mean and standard deviation of role of opinion leadership in diffusion of agricultural innovation was 18.89 and 3.71 respectively. The respondents were classified into three categories namely, 'lowest role', 'moderate role' and 'highest role' on the basis of role of opinion leadership in diffusion of agricultural innovation scores. The respondents according to their role of opinion leadership in diffusion of agricultural innovation under the study are given in Table 01 . 
Table 01. Respondents according to their role in diffusion of agricultural innovation

\begin{tabular}{|c|c|c|c|c|}
\hline Categories & Respond & & Mean & Standard deviation (SD) \\
\hline & Number & Percent & \multirow{5}{*}{18.89} & \multirow{5}{*}{3.71} \\
\hline Lowest role (upto 18) & 63 & 54.80 & & \\
\hline Moderate role (19-23) & 40 & 34.80 & & \\
\hline Highest role (above 25) & 12 & 10.4 & & \\
\hline Total & 115 & 100 & & \\
\hline
\end{tabular}

Table 02. Distribution of the respondents according to their selected characteristics

\begin{tabular}{|c|c|c|c|c|c|c|}
\hline \multirow{2}{*}{ Characteristics } & \multirow{2}{*}{$\begin{array}{l}\text { Observed } \\
\text { range }\end{array}$} & \multirow{2}{*}{ Categories } & \multicolumn{2}{|c|}{ Respondent } & \multirow{2}{*}{ Mean } & \multirow{2}{*}{ SD } \\
\hline & & & No & Percent & & \\
\hline \multirow{3}{*}{ Age } & \multirow{3}{*}{$20-70$} & Young aged below (35 years) & & & \multirow{3}{*}{41.69} & \multirow{3}{*}{10.66} \\
\hline & & Middle aged (35-50 years) & & & & \\
\hline & & Old aged (above 50 years) & & & & \\
\hline \multirow{4}{*}{$\begin{array}{l}\text { Level of } \\
\text { education }\end{array}$} & \multirow{4}{*}{$0-17$} & Literate $(0)$ & & & \multirow{4}{*}{7.03} & \multirow{4}{*}{4.82} \\
\hline & & Primary education (1-5) & & & & \\
\hline & & Secondary education (6-10) & & & & \\
\hline & & Above secondary (above-10) & & & & \\
\hline \multirow{3}{*}{ Family size } & \multirow{3}{*}{$2-11$} & Small family (up to 4) & & & \multirow{3}{*}{5.24} & \multirow{3}{*}{1.38} \\
\hline & & Medium family (5-7) & & & & \\
\hline & & Large family (above 7) & & & & \\
\hline \multirow{3}{*}{ Annual income } & \multirow{3}{*}{$\begin{array}{l}83000- \\
1735000 \\
\end{array}$} & Low income & 19 & 16.52 & \multirow{3}{*}{334690} & \multirow{3}{*}{262900} \\
\hline & & Medium income & 68 & 59.13 & & \\
\hline & & High income & 28 & 24.35 & & \\
\hline \multirow{3}{*}{$\begin{array}{l}\text { Extent of advice } \\
\text { on adoption of } \\
\text { agricultural } \\
\text { innovation }\end{array}$} & \multirow{3}{*}{$13-29$} & Low extent of advice (below 20) & 37 & 32.17 & \multirow{3}{*}{20.85} & \multirow{3}{*}{3.38} \\
\hline & & $\begin{array}{l}\text { Medium extent of advice } \\
(20-25)\end{array}$ & 70 & 60.87 & & \\
\hline & & High extent of advice (above 25) & 8 & 6.96 & & \\
\hline \multirow{3}{*}{ Innovativeness } & \multirow{3}{*}{$28-71$} & Low innovativeness (below 40 ) & 22 & 19.13 & \multirow{3}{*}{50.17} & \\
\hline & & $\begin{array}{l}\text { Medium innovativeness } \\
(40-60)\end{array}$ & 79 & 68.70 & & 10.34 \\
\hline & & High innovativeness (above 60) & 14 & 12.17 & & \\
\hline & & Low participation (up to 30 ) & 71 & 61.7 & & \\
\hline $\begin{array}{l}\text { urganizational } \\
\text { participation }\end{array}$ & $8-100$ & Medium participation $(31-60)$ & 33 & 28.7 & 31.36 & 19.04 \\
\hline & & High participation (above 60) & 11 & 11.4 & & \\
\hline & & Low knowledge (below 50 ) & 37 & 32.17 & & \\
\hline $\begin{array}{l}\text { Agricuitural } \\
\text { knowledge }\end{array}$ & $43-59$ & Medium knowledge $(50-55)$ & 57 & 49.57 & 5166 & 383 \\
\hline & ת & High knowledge (above 55) & 21 & 18.26 & 31.00 & 3.05 \\
\hline & & $\begin{array}{l}\text { low motivational activities (below } \\
20 \text { ) }\end{array}$ & 10 & 8.70 & & \\
\hline $\begin{array}{l}\text { Motivational } \\
\text { activities }\end{array}$ & $16-27$ & $\begin{array}{l}\text { Medium motivational activities } \\
\text { below }(20-23)\end{array}$ & 73 & 63.5 & 22.14 & 2.82 \\
\hline & & $\begin{array}{l}\text { High motivational activities (above } \\
\text { 23) }\end{array}$ & 32 & 27.8 & & \\
\hline & & $\begin{array}{l}\text { Poor diffusion network } \\
\text { (below 30) }\end{array}$ & 27 & 23.48 & & \\
\hline $\begin{array}{l}\text { Diffusion } \\
\text { network }\end{array}$ & $17-45$ & $\begin{array}{l}\text { Moderate diffusion network } \\
(30-40)\end{array}$ & 81 & 70.43 & 32.54 & 6.40 \\
\hline & & $\begin{array}{l}\text { Sound diffusion network } \\
\text { (above 40) }\end{array}$ & 7 & 6.09 & & \\
\hline
\end{tabular}


Table 01 indicates that among the respondents, the highest proportion (54.8 percent) of the respondent opinion leaders belonged to the group of lowest role in diffusion of agricultural innovation followed by 34.8 percent in moderate role group and the lowest proportion 10.4 percent in highest role group in diffusion of agricultural innovation. Among the respondent opinion leaders overwhelming majority ( 89.6 percent) of the opinion leaders have the lowest to moderate role in diffusion of agricultural innovation.

Table 02 indicates that middle and young aged respondents constitute $76.52 \%$ of the respondents. It was found that appreciable proportions (67.82 percent) of the respondent opinion leaders were secondary to above secondary level educated. The medium size family constitutes the highest proportion (66.96 percent). Overwhelming majority 85\% respondents have medium to high income level. 60.87 percent of the respondents had medium extent of advice on adoption of agricultural innovation. For the group of low to medium innovativeness the maximum percentage was (87.83 percent) .The overwhelming majority percentage (90.43) was the category of the group of low to medium level organizational participation. Majority ( 49.57 percent) of the respondents fell in medium knowledge category. Respondent opinion leaders have medium motivational activities category constitutes the highest proportion (63.5 percent). Data of Table 02 reveals that majority (70.43 percent) of the respondents fell in moderate diffusion network category.

\section{Table 03. Rank order of role of opinion leadership in diffusion of agricultural innovation}

\begin{tabular}{|l|l|l|}
\hline Role of opinion leader & $\begin{array}{l}\text { Role Playing } \\
\text { Index (RPI) }\end{array}$ & Rank \\
\hline Obtain agricultural information from extension agent & 293 & 1 \\
\hline Participate in method demonstration & 252 & 2 \\
\hline Participate in result demonstration & 251 & 3 \\
\hline $\begin{array}{l}\text { Give farmers information obtained from mass media and extension } \\
\text { agent timely }\end{array}$ & 242 & 4 \\
\hline Visit upazila agricultural office for solution of particular problem & 220 & 5 \\
\hline Advice farmers to adopt agricultural innovation & 219 & 6 \\
\hline Obtain agricultural information from mass media channel & 215 & 7 \\
\hline Serve as assistant of extension agent & 172 & 8 \\
\hline Help farmers when they are in difficulties & 165 & 9 \\
\hline Serve as center of inter personal communication network & 143 & 10 \\
\hline
\end{tabular}

Table 04. Pearson's product moment co-efficient of correlation showing relationship between dependent and independent variables

\begin{tabular}{|c|c|c|c|c|}
\hline \multirow{2}{*}{$\begin{array}{l}\text { Dependent } \\
\text { variable }\end{array}$} & \multirow{2}{*}{ Independent variables } & \multicolumn{2}{|c|}{ Tabulated value } & \multirow{2}{*}{$\begin{array}{l}\text { Value of Co- } \\
\text { efficient of } \\
\text { correlation }\end{array}$} \\
\hline & & 0.05 level & 0.01 level & \\
\hline \multirow{10}{*}{$\begin{array}{l}\text { Role of opinion } \\
\text { leadership in } \\
\text { diffusion of } \\
\text { agricultural } \\
\text { innovation }\end{array}$} & Age & \multirow{10}{*}{0.182} & \multirow{10}{*}{0.238} & -0.047 \\
\hline & Level of education & & & $0.202^{*}$ \\
\hline & Family size & & & -0.133 \\
\hline & Annual income & & & 0.144 \\
\hline & $\begin{array}{l}\text { Extent of advice on adoption of } \\
\text { agricultural innovation }\end{array}$ & & & $0.236^{*}$ \\
\hline & Innovativeness & & & $0.185^{*}$ \\
\hline & Organizational participation & & & $0.210^{*}$ \\
\hline & Agricultural knowledge & & & $0.341^{* *}$ \\
\hline & Motivational activities & & & $0.229^{*}$ \\
\hline & Diffusion network & & & $0.253^{* *}$ \\
\hline
\end{tabular}

**: Con-elation is significant at the 0.01 level *: Correlation is significant at the 0.05 level 
Table 03 represents the ten aspects of role of opinion leadership in diffusion of agricultural innovation. As per Role Playing Index (RPI) allows to obtain agricultural information from extension agent positioned the 1 st, participate in method demonstration in $2^{\text {nd }}$, participate in result demonstration in

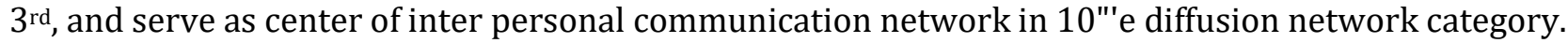

Pearson Product Moment Correlation Co-efficient was computed in order to find out the extent of relationship between the dependent variable and independent variables (Table 04). To reject or accept the null hypothesis 0.05 level of probability was used. A statistically significant and nonsignificant relationship was observed when the computed value or " $r$ " was greater or smaller than the tabulated value, respectively.

Level of education, extent of advice on adoption of agricultural innovation, innovativeness, organizational participation, agricultural knowledge, motivational activities and diffusion network had significant positive relationships with role of opinion leadership in diffusion of agricultural innovation. Annual income had no significant positive relationships with role of opinion leadership in diffusion of agricultural innovation. On the other hand, age and family size had no significant negative relationship with role of opinion leadership in diffusion of agricultural innovation.

Higher Level of education, extent of advice on adoption of agricultural innovation, innovativeness, organizational participation, agricultural knowledge, motivational activities and diffusion network of opinion leaders can increase their role in diffusion of agricultural innovation. This is possibly due to the fact that the local leaders are usually innovative and they generally more risk oriented dynamic, educated and knowledgeable. These qualities encourage them to adopt new ideas and practices and disseminate them among the fellow farmers. So in order to increase the role of opinion leaders in diffusion of agricultural innovation, agricultural technology development institute, DAE and other leadership development organization may arrange training for the local leaders for playing more active role in diffusion of agricultural innovation. About 94 percent local leaders have low to medium diffusion network, so it is necessary to undertake proper initiatives for increasing diffusion network of opinion leaders in diffusion of agricultural innovation.

\section{Conclusion}

Pearson Product Moment Correlation Co-efficient between dependent and independent variable that education level, extent of advice on adoption of agricultural innovation, innovativeness, organization participation, agricultural knowledge, motivational activities and diffusion network had significant positive relationships with role of opinion leadership in diffusion of agricultural innovation. Annual income had no significant relationship with the role of opinion leadership in diffusion of agricultural innovation. On the other hand, age and family size had no significant negative relationship with role of opinion leadership in diffusion of agricultural innovation under the present study. Therefore the role of opinion leadership in diffusion of agricultural innovation can be increased through emphasis on education, extent of advice on adoption of agricultural innovation, innovativeness, organization participation, agricultural knowledge, motivational activities and diffusion network of local leaders.

\section{References}

[1]. BBS (Bangladesh Bureau of Statistics) (2015). Statistical Yearbook of Bangladesh-2012. Statistics Division, Ministry of Planning, Government of the People's Republic of Bangladesh, Dhaka.

[2]. Bhuiyan, M. H. (2012). Generation and diffusion of agricultural innovation. Gurpukur Research Institute, Dhaka.

[3]. Dennis, L. P. \& Andersion. R. A. (1998). A World Bank operations evaluation study. Agricultural Extension and Research.

[4]. Heemskerk, W. (2005). Participatory approaches in agricultural research and development. Retrieved July 17, 2009, from http://knowledge.cta.int/en/Dossiers/Demanding-Innovation/ Participatory-approaches-in-ARD/Articles/Participatory-approaches-in-agricultural research- 
and-development.

[5]. Mettric, H. (1993). Development oriented research in agriculture. ICRA, Wageningen, Netherlands.

[6]. Monge, M., Hartwich, F. \& Halgin, D. (2008). How change agents and social capital influence the adoption of innovations among small farmers. Discussion Paper 00761. Washington, DC. International Food Policy Research Institute.

[7]. Rogers, E. M. (1983). Diffusion of innovations. The free press, Collier Macmillan Publishers. London.

[8]. Rogers, E. M. (2003). Diffusion of innovations (5th.ed). New York, NY. Free press.

\section{HOW TO CITE THIS ARTICLE?}

\section{APA (American Psychological Association)}

Islam, K. A., Bashar, M. A., Akhter, N., Mia, M. A. T., Afroj, M., Rahman, M. M.\& Baque, M. A. (2016). Diffusion of agricultural innovation through opinion leadership. International Journal of Business, Management and Social Research, 02(02), 125-131.

\section{MLA (Modern Language Association)}

Islam, K. A., Bashar, M. A., Akhter, N., Mia, M. A. T., Afroj, M., Rahman, M. M. \& Baque, M. A. "Diffusion of agricultural innovation through opinion leadership." International Journal of Business, Management and Social Research, 02.02 (2016): 125-131.

\section{Chicago/Turabian}

Islam, K. A., Bashar, M. A., Akhter, N., Mia, M. A. T., Afroj, M., Rahman, M. M. \& Baque, M. A. Diffusion of agricultural innovation through opinion leadership. International Journal of Business, Management and Social Research, 02, no. 02 (2016): 125-131. 